\title{
Research Note On The Incremental Value Of Knowledge Workers
}

\author{
Aya S. Chacar, Florida International University \\ Russell W. Coff, Emory University \\ Krishnamurthy Surysekar, Florida International University
}

\begin{abstract}
As firms seek to manage knowledge, they rely increasingly on knowledge workers. The assumption is often that the incremental value from hiring these knowledge workers accrues to firms, but theory indicates that it may not. In this research note, we examine this question. We perform a cross-sectional study of 30 investment banks in the period 1992-96. We use gross value of mergers and acquisitions business as a proxy for gross performance, and pre-tax operating income as a proxy for net performance. The dependent variable and measure of knowledge workers is the number of "star" analysts, as measured by Wall Street Journal/Zacks rankings. Our results strongly support the hypothesis that the number of star analysts in investment banking is positively associated with gross performance, and weakly support the hypothesis that they are not positively associated with net performance. If future research could generalize these conclusions, they could have implications for design of compensation systems in industries significantly employing knowledge workers.
\end{abstract}

Keywords: Knowledge-Based Employees, Incentives; Performance Measurement

\section{INTRODUCTION}

$\mathrm{n}$ their comprehensive review of the knowledge management (KM) literature, Alavi and Leidner (2001) note the need for research on incentives that would motivate employees in the present knowledge-based economy. A number of articles recognize the key issue of evaluating the performance of these knowledge-based employees. Some (Businessline, April 2006, p.1) have argued for variable pay, bonuses, sharing them with other organizations, etc. Based on an international survey of R\&D professionals, Manolopoulos (2006) notes that economic and extrinsic rewards are largely preferred by these knowledge workers. Rousseau and Shperling (2004) note that the roles of owner, manager and worker appear to be converging for knowledge workers, particularly in knowledge-intensive firms. Arguing for a greater weight on team and firm-level performance metrics in evaluating individuals, Van Alstyne (2005) points out that the people rewarded for individual performance shared information least; the people rewarded for team performance shared more; and the people rewarded for company performance shared most. A cursory reading of firm annual reports would reveal that most firms tout their employees as their greatest assets. However, what happens to any incremental value that accrues to the firm due to the talented employees? Who, between the employees and the shareholders, garners the lion's share of this incremental value? We address this question in this research note. We focus on the investment banking industry, where the complexities surrounding financial disclosures by firms have made "stars" out of research analysts.

\section{KNOWLEDGE-BASED EMPLOYEES AND DIVIDING UP THE PIE}

Managers are expected to make decisions keeping in mind the best interests of the shareholders. However, agency theory (see Jensen and Meckling 1973) predicts that managers and owners may have divergence of preferences. With superior information regarding the firm's environment, and the owners' lack of ability at perfect monitoring of their actions, managers need to have incentives to motivate them to act in the best interests of the owners, i.e., 
shareholders. Moreover, employees may necessitate additional compensation to invest in firm-specific knowledge (Castanias and Helfat, 2001).

Let us consider an investment banking firm that employs star analysts. These analysts help the firm, through their research outputs, acquire clients for mergers and acquisitions (M\&A). One measure of "gross value" would be the volume of M\&A business, on which the firm's revenue is based.

Thus, we could look at the following two equations:

$$
\mathrm{GVA}=\Delta
$$

$\mathrm{NVA}=\Delta$ - Comp, where

GVA represents the gross value accruing the shareholders,

NVA represents the net value accruing the shareholders, due to hiring knowledge workers,

$\Delta$ represents the gross additional value for the firm generated by knowledge workers, and

Comp represents the compensation of the knowledge workers.

In this relationship, Comp is the only term that has to be positive. Thus, $\Delta<0$, or $\Delta<\mathrm{Comp}$, can lead to NVA $<0$.

Compensation to the knowledge workers would be significantly influenced by their bargaining power. Coff (1999) and Chacar and Coff (2000) discuss a number of reasons why knowledge workers may enjoy superior bargaining power with shareholders. These include their bargaining as a team (an example being the "Flaming Ferraris" at Credit Suisse First Boston), their access to superior information, and high cost to replace them. Knowledge workers also may have superior bargaining power because they 'own' the relationships, or social capital, that help bring income to the firm and hence can credibly threaten to exit (Coff and Blyler, 2003). Finally, the institutional environment, both the formal and informal rules of the games (North, 1990), may also influence the power of employees (Chacar \& Hesterly, 2008)

\section{KNOWLEDGE-BASED EMPLOYEES AND FIRM PERFORMANCE}

As we noted in the previous section, it is instructive to look at both gross benefits to the firm, and the net benefits to the stockholders, of hiring knowledge workers.

\section{Gross Performance}

Gross performance refers to measures that are relatively insensitive to which stakeholders appropriate the rent. Variables such as sales and market share, along with incremental changes in these measures are good indicators of how firms perform relative to their rivals. They do not indicate who reaps the gains from the performance (e.g., employees, suppliers, shareholders, etc.).

Any advantage accruing from hiring knowledge-based employees should be evident in measures of gross performance, which focus more on product market outcomes. Thus, even if star analysts do not influence residual performance, they will have an impact on gross performance. For the above reasons, we focus on volume of mergers and acquisitions business generated in a year as the gross performance measure, since revenues to the firm is often a small percentage of this figure. Thus, our first hypothesis is:

H1: All else being equal, gross performance of investment banks is positively associated with the number of "star" research analysts they employ.

\section{Net Performance}

If a firm enjoys a competitive advantage because of its knowledge-based employees (e.g., rainmakers), it may also be ceding rent to such employees. Therefore the advantage may not manifest in measures of net performance. 
When employees are in a strong position to appropriate rent arising from their human and social capital, we would expect this type of advantage to be less detectable using measures of net performance. As suggested earlier, this is especially the case for research analysts. In this paper, we use operating income as a measure of net performance. This measure captures the effect of compensation to the star analysts. However, it is not influenced by a number of accounting adjustments, for example, due to extraordinary events, disposal of segments, and changes in accounting principle.

H2: All else being equal, net performance of investment banks is not positively associated with the number of "star" research analysts they employ.

\section{METHODS $^{1}$}

The hypotheses developed are tested over a four-year time frame in the investment banking industry. Considering the pooled nature of the data used in this study, the models used are estimated using a cross-sectional time series regression with a GLS random-effects estimator.

\section{Sample}

We collected data for the top 30 investment banks during the 1992-1996 time period. These companies, on average, were responsible for about $70 \%$ of the overall volume of mergers \& acquisitions that relied on advisors and for $90 \%$ of corporate finance deals (underwriting). The final analysis only included four years of data because we lagged the dependent variables by one year.

The data collection for this project involved numerous data sources. Financial data for the public companies in the sample was collected from COMPUSTAT, and from companies' annual and 10k reports. Data on industry expertise, firm coverage and the total number of analysts was obtained from the I/B/E/S database and the Nelson Directory. Data on rankings of star analysts was collected from the Institutional Investor magazine survey and from the Wall Street Journal/Zacks Investment Research survey. Information on the volume of M\&A deals by advisor was obtained from the Securities Data Corporation database.

\section{Dependent Variables}

Gross Performance: Gross Performance is measured by the sum of the estimates of volume of mergers and acquisitions business associated with advising acquirers and target firms. The M\&A volume was obtained from the Securities Data Corporation Database ${ }^{2}$. This approach assumes a common fee structure for all firms providing each type of service and that the fees depend, in varying degrees, on the size of the transaction. These assumptions have been well documented and are reflected in the following excerpt from Brown Brothers \& Harriman's web page:

$B B H \& C o$. seeks to align its own interests with those of its clients. Accordingly, in a typical sell-side engagement, we structure most of our compensation in the form of a success fee payable at the close of a transaction. The success fee is typically calculated based on a percentage of the business value (i.e., the equity value plus assumed funded debt) of the company being sold. We also typically receive a modest monthly retainer and are reimbursed for out-ofpocket expenses. For buy-side engagements, we also receive a success fee, a modest monthly retainer, and reimbursement of expenses. However, rather than having the success fee based on a percentage of the purchase price (which could lead to a misalignment of interests), we typically structure the success fee as a fixed dollar amount. Brown Brothers \& Harriman (www.bbh.com, 1999).

\footnotetext{
${ }^{1}$ In this section, we draw significantly from the discussion in Chacar and Coff (2000).

2 The results were identical when we considered each separately.
} 


\section{Net performance}

We have used pre-tax operating income (OPInc) to measure the net benefit to the shareholders ${ }^{3}$. This strips away many of the accounting assumptions and extraordinary items that may affect and distort net income. As such, it should be a relatively sound measure of net performance.

\section{Independent Variable}

We used the Zacks/Wall Street Journal ranking of analysts for our independent variable. This is based on objective data on the quality and accuracy of the analysts' work, and thus emphasizes human capital. WSJStars is the number of "star" analysts working for the firm, based on both the analysts" ability to pick stocks and their ability to predict earnings accurately. Thus, it is a broader objective measure of analyst's abilities.

\section{Control Variables}

We have used four control variables to capture firm-level factors that influence performance.

BrokerSize: This is the number of analysts at a particular broker for each year. In general, size or scale of operations has a linear relationship with performance measures. It may especially influence gross measures of performance such as revenue or market share. The expected sign of this measure is positive.

NumReports: This is the number of analyst reports issued per year. Companies with analysts writing a large number of reports may be focusing on generic analysis that will be negatively associated with M\&A performance, but which is possibly positively associated with commissions. Thus, the impact of this variable on operating income is not clear.

NumFirms: This refers to the number of firms that the company covers. Ceteris paribus, the more companies the firm follows, the more likely is to generate M\&A fees and commissions, and thus, income. This is also clearly linked to the scale and scope of operations.

Num Industries: This also refers to the breadth of coverage in the research department. The impact of this variable on performance is not clear. On one hand, increased industry coverage might bring in more business (like NumFirms). However, there is some feeling among practitioners that it may be better to focus on a few industries (e.g., boutique investment banking firms) and gain a reputation for that specialization.

Year: This variable controls for any potential time trends. One would expect this variable to be positive for the time period in the sample, since the market as a whole was expanding at this time.

We run two regression models:

Model 1: Gross Performance $=\mathrm{f}($ WSJStars, BrokerSize, NumReports, NumFirms, NumIndustries, Year $)$

Model 2: Net Performance $=\mathrm{g}($ WSJStars, BrokerSize, NumReports, NumFirms, NumIndustries, Year)

\section{RESULTS}

\section{Star Analysts And Performance}

Table 1 presents the regression results on gross performance, measured by the total volume of M\&A transactions advised, and net performance, measured by Operating Income before income taxes.

\footnotetext{
${ }^{3}$ Note that this paper is part of a larger project that explores a wider variety of performance measures.
} 
Table 1

Star Analysts and Performance

\begin{tabular}{|c|c|c|}
\hline & $\begin{array}{c}\text { Model 1 } \\
\text { (Gross Performance) }\end{array}$ & $\begin{array}{c}\text { Model 2 } \\
\text { (Net Performance) }\end{array}$ \\
\hline BrokerSize & $465.8^{*}$ & $16.3^{* * *}$ \\
\hline NumReports & $-32.1^{* *}$ & -0.1 \\
\hline NumFirms & $152.5^{* * *}$ & 0.4 \\
\hline NumIndustries & $-259.1^{*}$ & -1.3 \\
\hline Year & 1514.3 & -5.3 \\
\hline WSJStars & $2058^{* * *}$ & -5.1 \\
\hline $\mathrm{R}^{2}$ & 0.55 & 0.77 \\
\hline
\end{tabular}

The estimation is done using a cross-sectional time-series regression with a GLS random-effect estimator. Coefficients are shown with significance indicated as follows: $* * *=.001, * *=.01, *=.05, \dagger=.1 . \mathrm{N}=156$ cases.

Gross performance is measured by the volume of Mergers and Acquisitions business in a year for the firm. Net performance is measured by Operating Income before income taxes for the firm for the year.

The regression results for Model 1 (gross performance) support H1. The coefficient of WSJStars is positive and significant at $1 \%$. However, the results of the Model 2 regression show that stars do not add to the firm's bottom line, supporting H2. In fact, the coefficient on WSJStars is negative, though not significant. We had predicted that such knowledge-based assets might be positively associated with gross performance (H1), but not with net performance (H2). The results are consistent with our prediction.

Thus, we can conclude that there is limited evidence consistent with the argument that value that is created by knowledge workers does not accrue to shareholders, because such workers appropriate what they create, by way of rents. Our results also have implications for compensation system design when dealing with knowledge workers in general, if these results hold up in other relevant contexts.

\section{Limitations And Future Directions For Empirical Research}

That said, the results from this study must be interpreted cautiously for a variety of reasons. First, we presented only two outcome measures representing gross and net performance. Future research should explore a much wider variety of measures. Second, the fact that some of the firms in the investment banking industry are private or have operations beyond investment banking makes the accounting measures somewhat suspect. The results would also have to be replicated in other industries employing knowledge workers, like data processing, healthcare, etc., before generalized conclusions can be drawn.

\section{ACKNOWLEDGEMENTS} Professorship.

Krishnamurthy Surysekar gratefully acknowledges the Morrison, Brown, Argiz and Farra, LLP

\section{REFERENCES}

1. Alavi, M., and Leidner, D.E. (2001). Review: Knowledge Management and Knowledge Management Systems: Conceptual Foundations and Research Issues. MIS Quarterly, 25(1),107-136.

2. Castanias R.P., and Helfat C.E. 2001. The managerial rents model: theory and empirical analysis. Journal of Management, 27, 661-678.

3. Chacar, A.S. and Coff, R. (2000). The Knowledge-Based Employees Paradox. In Bresser, R., Hesuskel, D. and Nixon, R. (Eds.) Winning Strategies in a Deconstructing World. John Wiley \& Sons Ltd: London, UK.

4. Chacar, A., and Hesterly, W. (2008). Institutional Settings and Rent Appropriation by Knowledge-Based Employees: The Case of Major League Baseball, Managerial and Decision Economics, forthcoming. 
5. Coff, R. (1999). When Competitive Advantage Doesn't Lead to Performance: Resource-based Theory and Stakeholder Bargaining Power. Organization Science, 10(2), 119-133.

6. Coff, R.W., and Blyler, M. (2003). Dynamic capabilities, social capital, and rent appropriation: Ties that split pies. Strategic Management Journal, 24(7), 677-686.

7. Jensen, M.C., and Meckling, W.H. (1973), Theory of the Firm: Managerial Behavior, Agency Costs and Ownership Structure, Journal of Financial Economics 3, 305-360.

8. Manolopoulos, J. (2006). What motivates R\&D professionals? Evidence from decentralized laboratories in Greece. The International Journal of Human Resource Management, 17(4), 616-647.

9. North, D.C. (1990). Institutiona, Institutional Change and Economic Performance. Cambridge University Press: Cambridge.

10. Rousseau, D.M., and Shperling, Z. (2004). Ownership and the Changing Employment Relationship: Why Stylized Notions of Labor No Longer Generally Apply - A Reply to Zardkoohi and Paetzold. Academy of Management: The Academy of Management Review, 29(4), 562-569.

11. Schonfeld, E. (1998). Quattrone \& Co. Abandon Deutsche Bank, Fortune 138(3), 168.

12. Van Alstyne, M.W. (2005). Create Colleagues, Not Competitors, Harvard Business Review, 83(9), 24-28

\section{NOTES}

